\title{
Laboreal
}

Volume $6 \mathrm{~N}^{\circ} 1$ | 2010

Varia

\section{Taylorismo, racionalização, selecção, orientação}

Taylorismo, racionalización, selección, orientación

Taylorisme, rationalisation, sélection, orientation

Taylorism, rationalization, selection, orientation

\section{Henri Wallon}

Tradutor. Andreia Ferreira

\section{OpenEdition}

\section{Journals}

\section{Edição electrónica}

URL: http://journals.openedition.org/laboreal/9212

DOI: 10.4000/laboreal.9212

ISSN: 1646-5237

\section{Editora}

Universidade do Porto

\section{Refêrencia eletrónica}

Henri Wallon, «Taylorismo, racionalização, selecção, orientação », Laboreal [Online], Volume 6 NN$^{0} 1$ |

2010, posto online no dia 01 julho 2010, consultado o 24 setembro 2020. URL : http://

journals.openedition.org/laboreal/9212 ; DOI : https://doi.org/10.4000/laboreal.9212

Este documento foi criado de forma automática no dia 24 setembro 2020.

\section{c) (i) (8)}

Laboreal está licenciado com uma Licença Creative Commons - Atribuição-NãoComercial 4.0 Internacional. 


\title{
Taylorismo, racionalização, selecção, orientação
}

\author{
Taylorismo, racionalización, selección, orientación \\ Taylorisme, rationalisation, sélection, orientation \\ Taylorism, rationalization, selection, orientation
}

\author{
Henri Wallon \\ Tradução : Andreia Ferreira
}

\section{REFERÊNCIA}

Artigo original : Wallon, H. (1947). Taylorisme, rationalisation, sélection, orientation. Technique, Art, Science. Octobre, 5-7.

1 Logo no início do século expandiu-se na América, em Inglaterra e em França o livro de Taylor sobre "A organização científica do trabalho", que foi objecto de reacções muito vivas. Em França, ele foi sustentado por um homem de ciência, Le Châtelier, professor no Collège de France; os métodos por ele preconizados estavam a ser aplicados em algumas empresas, nomeadamente os estabelecimentos Arbel; mas a classe operária, pelo que conta um Nerrheim em "La Vie Ouvrière", mostrava-se francamente hostil e Laby, em nome da psicotécnica recente, endereçou-lhe críticas severas. Em Inglaterra, a oposição pareceu vir sobretudo dos engenheiros, não convencidos pelo seu colega americano [1].

2 Ele marca portanto uma data capital. Ele teve grandes consequências, tanto ideológicas como práticas ou antes um índice de transformações profundas que operaram nas relações do homem e da técnica. Até então, parecia que o homem deveria manter-se alheio à técnica. Ele criou-a, ele utiliza-a, mas como um instrumento de que ele deve manter-se mestre. $O$ objecto e o instrumento da técnica não podiam ser mais que coisas, porque ela apoia-se nas leis que governam as coisas. Mas a actividade do homem obedece a essas leis? Mesmo quando o homem foi maltratado no seu trabalho, por 
exemplo sob o regime da escravatura onde ele foi utilizado como força motriz, sempre foi tratado como pessoa moral. Ele era repreendido como um ser responsável pela sua preguiça e pela sua falta de habilidade. Eram essas reacções globais as referidas. A ciência decompôs gradualmente as coisas nos seus elementos, reportava a diversidade variável dos efeitos a factores físicos definidos; o homem, ao contrário, parecia um livre arbítrio que se pode influenciar, mas nele mesmo indissociável.

3 Não há que se oponha mais a este dogma espiritualista do que os princípios do Taylor. Estes consagram uma observação já feita mais de cem anos antes sobre as relações do homem e da máquina por economistas como Adam Smith, que notaram que ela reduz frequentemente a actividade do operário a alguns gestos limitados e sempre os mesmos. Consequência antes lastimável na sua opinião, regra a generalizar segundo Taylor. Porque, de facto, não incorporar o homem na máquina tratando-o como a ela, visto que o seu trabalho comum é incorporado, sem distinção possível, no objecto fabricado ? O acto de fabricação em si não é uma estrutura na qual os movimentos do homem e da máquina não fazem mais do que se completar? Os movimentos desta regulam-se rigorosamente, porque não os movimentos daquele? Taylor tinha imaginado métodos precisos para o corte dos metais, porquê comprometer os resultados desse rigor deixando subsistir essa margem de indeterminação que é a intervenção do operário? Porquê deixá-lo escapar ao determinismo quando o progresso da ciência tende a demonstrar a sua universalidade?

4 A inovação de Taylor, que ele considerava natural e de uma evidência incontestável, é estender ao gesto do homem as mesmas preocupações de precisão e de economia que no uso da máquina. A qualquer trabalho devem responder certos movimentos particularmente bem adaptados e que é preciso reconhecer, seleccionar, ensinar, impor.

5 Mesmo o trabalho mais simples não pode escapar-se a esta lei : tal como o de quem transporta fardos pesados. Taylor estudou minuciosamente a manobra que consiste em transportar blocos de ferro fundido, e ele aplicou-se em diminuir a fadiga, aumentar o rendimento eliminando os gestos que os acompanham sem utilidade e frequentemente como um obstáculo. 0 mesmo para o pedreiro que montará o muro tanto mais rápido quanto encontrar os tijolos mais à sua mão. 0 mesmo para o utilizador da pá de carvão ou de terra cujos movimentos devem ser solidários com a pá ou reciprocamente, isto quer dizer que ela deve ter um cumprimento de cabo, uma forma, uma capacidade relacionados com as características físicas do operário ao mesmo tempo que com o objecto da manutenção. 0 mesmo enfim para o operário metalúrgico. Não é suficiente ele indicar exactamente regulação do seu torno, ele deve também regular o seguimento das suas atitudes e dos seus gestos. Mas não é possível fazê-lo à priori : o movimento a fazer, é preciso estudá-lo com operários qualificados, foi preciso analisá-lo, cronometrá-lo em cada uma das suas partes, recompô-lo e cronometrá-lo no seu conjunto. Quando ele é finalmente afinado, instrutores demonstram aos operários e ficarão vigilantes em permanência para assegurar a execução correcta.

6 Esta tentativa, de interesse puramente técnico, foi uma verdadeira revolução. Não apenas porque ela chocava com as ilusões, as rotinas, os abusos espiritualistas, mas porque ela chocava com as leis fisiológicas, psíquicas e sociológicas da natureza humana. Esta oposição foi fecunda. Chocando, o Taylorismo levou à saída do silêncio necessidades que se ignoravam. Por uma espécie de movimento dialéctico, com 
repercussões alternantes, ele foi a origem da racionalização industrial, da selecção e da Orientação profissional.

7 A racionalização. Taylor evidenciou-a mal, mas ele tinha-a preconizado, se bem que de uma forma ainda muito limitada por um lado, demasiado extensiva e, por isso perversa, por outro. Quando ele recomendava um dispositivo que dispensa o pedreiro de se baixar para pegar cada tijolo, ou as pás diferentes para aqueles que a manejam com a mão direita ou com a mão esquerda, ele ajusta a ferramenta ao operário, isto quer dizer que com menos fadiga ele obtém um rendimento melhor. Ele estava exactamente na linha da racionalização. Mas ele só via ainda a relação imediata do instrumento e do gesto. Ele não considerava suficientemente o ambiente do atelier, e em primeiro lugar o seu ambiente material, a ventilação, a iluminação, a higrometria, todas circunstâncias que interessam antes de tudo à fisiologia do trabalhador, e então também, o seu rendimento imediato. Mas sobretudo a preocupação quase exclusiva que tinha Taylor do mecanismo operatório levou-o a que se ocupasse unicamente dos movimentos do operário da mesma forma como considerava os movimentos de um torno. Realçar os momentos úteis, suprimir os tempos mortos e os gestos parasitas era o seu objectivo. $\mathrm{E}$ a manobra assim regulada, impô-la numa cadência abaixo da qual não se podia descer. Fazendo assim, este engenheiro cometia uma heresia de principiante. Ele demolia a máquina humana que tem tipos variáveis de organização conforme os indivíduos e que deve funcionar ao ritmo de cada um, segundo as combinações de movimentos que não são os mesmos para todos mas não deixam de ser relacionados com a constituição fundamental de cada um.

8 O resultado desta imposição foi o enfraquecimento e a eliminação rápida dos que que, tendo tido sucesso provisoriamente a suportar este regime, foram de seguida atirados para a repulsa. Quanto aos outros, uma espécie de selecção prévia exercia-se contra eles. Sistematizar aquilo que tinha sido primeiro a consequência de exigências excessivas conduzia à introdução de um exame de selecção na contratação dos operários. Com ela também, Taylor aparecia como um pioneiro. No entanto, ele próprio não compreendeu bem o princípio. Preconizando a "organização científica do trabalho" ele não se libertou, contudo, completamente dos erros antigos. A selecção não era para ele um simples teste de aptidões. Ele juntou o interesse pessoal do trabalhador e, aqui ainda, da forma mais desastrada. Como ele não tinha tido em conta a sua fisiologia, ele não considerou a sua psicologia.

9 Forçando a cadência do trabalho, ele exige mais do operário. Como fazê-lo consentir esse acréscimo de esforço ? O reenvio do recalcitrante ou do incapaz, primeiro meio. Mas ele precisa também de estimular por outro meio que não o medo. Aquele que consegue realizar com uma rapidez maior deve ganhar mais. Mas não proporcionalmente ao seu rendimento. Porque ganhar demais torna o operário irregular no seu trabalho e preguiçoso. A necessidade não pode desaparecer das suas preocupações. Convém atribuir-lhe uma simples bonificação que alguns calcularam que cobria à justa o preço das calorias suplementares exigidas pelo aumento da intensidade do trabalho.

Definitivamente, Taylor não cessa de considerar o homem como uma simples máquina que é preciso utilizar o mais economicamente possível. É aliás um desígnio que ele declarou formalmente. Uma vez no trabalho, o trabalhador deve estar inteiramente entregue às directrizes de quem o emprega. Nada seria mais deplorável do que lhe deixar a menor iniciativa. Toda a iniciativa é reflexão, toda a reflexão perda de tempo e 
anarquia. É necessário um gabinete de estudos que regulará soberanamente os gestos, as velocidades e os prémios. Cada um depende individualmente deste gabinete. Entre os operários, não é admitida nenhuma solidariedade de interesses. Todos tratados como máquinas do mesmo tipo, mas cada um uma máquina completamente distinta das outras.

11 Esta mutilação do trabalhador, expressamente querida por Taylor, deveria naturalmente voltar-se contra o sistema, porque está em oposição com as necessidades mais essenciais do ser humano. A fisiologia fez rapidamente justiça aos gestos e aos ritmos impostos. A psicologia revela porque o apelo ao interesse puramente individual deve levar também à falência. $O$ homem isolado está na defensiva. Ele não sabe entregar mais que uma parte mais ou menos reduzida do trabalho. Há a retenção de energias. Para que elas sejam libertadas, era preciso uma verdadeira entrega do trabalhador à sua obra. Essa entrega tornou-se impossível pelo egoísmo dos métodos que Taylor tentou impor aos trabalhadores. Como foi dito, já há alguns anos, por psicólogos soviéticos : o regime capitalista é feito de tal forma que ele não poderá nunca libertar o potencial de trabalho que existe em cada um.

Se indiferente, se hostil mesmo às necessidades da pessoa humana, o Taylorismo não podia descobrir a Orientação profissional, que se opõe à selecção como o ponto de vista do indivíduo pode opor-se às únicas exigências de uma determinada tarefa. Ela tem como objectivo encontrar para cada um o emprego que melhor lhe convém, que é mais conforme não só às suas aptidões, mas aos seus gostos e aos seus interesses bem compreendidos. Assim, ela serve também o interesse geral ao evitar a constituição desse resíduo de menor qualidade que resulta da selecção e que se arrisca a pesar na economia do país em benefício apenas de algumas empresas privilegiadas. No entanto o seu contacto com a realidade impôs a Taylor algumas observações que fizeram pressentir a orientação. Assim as separadoras de berlindes que ele constatou serem as mais rápidas não eram habitualmente as mais inteligentes. A uma inteligência medíocre pode então corresponder aptidões mais ou menos incompatíveis com um espírito mais desperto. E é evidentemente o papel da orientação utilizar essas diferenças de sentido inverso para distribuir cada um no posto de trabalho onde ele deve ser melhor sucedido.

Pelo carácter grosseiro destes procedimentos, que eram muitas vezes contrários à natureza fisiológica e psíquica do homem, o Taylorismo ergueu as dificuldades e as reacções que foram o ponto de partida de progressos importantes. Ele finalmente contribuiu para impor aquilo que ele tendia a desconhecer ou suprimir. Ele é um exemplo claro daquelas oposições que se resolvem em descobertas ou em etapas novas. A mecanização dos trabalhadores explicitamente querida por Taylor transformou-se em estrita necessidade em fazer direito a todas as exigências da natureza humana, exigências não somente fisiológicas, mas psíquicas, sociais e morais. 


\section{NOTAS}

1. Nos seus livros "La crise du progrès" e "Problèmes humains du machinisme industriel", Georges Friedmann fez do Taylorismo um estudo notável. http://laboreal.up.pt/revista/ artigo.php?id=37t45nSU5471122987295752361 